\title{
Genetic and structural analysis of the essential fission yeast RNA polymerase II CTD phosphatase Fcp1
}

\author{
BEATE SCHWER, ${ }^{1}$ AGNIDIPTA GHOSH, ${ }^{2}$ ANA M. SANCHEZ, ${ }^{1}$ CHRISTOPHER D. LIMA, ${ }^{2,3}$ \\ and STEWART SHUMAN ${ }^{4}$ \\ ${ }^{1}$ Microbiology and Immunology Department, Weill Cornell Medical College, New York, New York 10065, USA \\ ${ }^{2}$ Structural Biology Program, ${ }^{3}$ Howard Hughes Medical Institute, ${ }^{4}$ Molecular Biology Program, Sloan-Kettering Institute, New York, \\ New York 10065, USA
}

\begin{abstract}
Protein phosphatases regulate mRNA synthesis and processing by remodeling the carboxy-terminal domain (CTD) of RNA polymerase II (Pol2) to dynamically inscribe a Pol2 CTD code. Fission yeast Fcp1 (SpFcp1) is an essential 723-amino acid CTD phosphatase that preferentially hydrolyzes Ser2- $\mathrm{PO}_{4}$ of the YS ${ }^{2} \mathrm{PTSPS}$ repeat. The SpFcp1 catalytic domain (aa 140-580) is composed of a DxDxT acyl-phosphatase module (FCPH) and a BRCT module. Here we conducted a genetic analysis of SpFcp1, which shows that (i) phosphatase catalytic activity is required for vegetative growth of fission yeast; (ii) the flanking amino-terminal domain (aa 1-139) and its putative metal-binding motif $\mathrm{C}^{99} \mathrm{H}^{101} \mathrm{Cys}^{109} \mathrm{C}^{112}$ are essential; (iii) the carboxyterminal domain (aa 581-723) is dispensable; (iv) a structurally disordered internal segment of the FCPH domain (aa 330-393) is dispensable; (v) lethal SpFcp1 mutations R271A and R299A are rescued by shortening the Pol2 CTD repeat array; and (vi) CTD Ser2- $\mathrm{PO}_{4}$ is not the only essential target of SpFcp1 in vivo. Recent studies highlight a second CTD code involving threonine phosphorylation of a repeat motif in transcription elongation factor Spt5. We find that Fcp1 can dephosphorylate Thr1- $\mathrm{PO}_{4}$ of the fission yeast Spt5 CTD nonamer repeat T ${ }^{1}$ PAWNSGSK. We identify Arg271 as a governor of Pol2 versus Spt5 CTD substrate preference. Our findings implicate Fcp1 as a versatile sculptor of both the Pol2 and Spt5 CTD codes. Finally, we report a new $1.45 \AA$ crystal structure of $\mathrm{SpFcp} 1$ with $\mathrm{Mg}^{2+}$ and $\mathrm{AlF}_{3}$ that mimics an associative phosphorane transition state of the enzyme-aspartyl-phosphate hydrolysis reaction.
\end{abstract}

Keywords: CTD code; Spt5; Ssu72

\section{INTRODUCTION}

The carboxyl-terminal domain (CTD) of the Rpb1 subunit of RNA polymerase II (Pol2) consists of tandemly repeated heptapeptides with the consensus sequence $\mathrm{Y}^{1} \mathrm{~S}^{2} \mathrm{P}^{3} \mathrm{~T}^{4} \mathrm{~S}^{5} \mathrm{P}^{6} \mathrm{~S}^{7}$. Phosphorylation of Tyr1, Ser2, Thr4, Ser5, and Ser7 and cis-trans isomerization of Pro3 and Pro6 inscribe a CTD code with up to $128^{n}$ potential primary structures (where $n$ is the number of heptads). The CTD code provides information about the state of the transcription machinery that is read by CTD receptor proteins that control transcription, modify chromatin structure, and catalyze or regulate RNA maturation (Corden 2013; Eick and Geyer 2013; Bentley 2014). The CTD undergoes waves of serine, threonine, and tyrosine phosphorylation and dephosphorylation during the transcription cycle. The instantaneous information content of the CTD reflects the balance between the activities of position-specific CTD kinases and CTD phosphatases that act as writers and erasers of the phosphorylation code.

Corresponding authors: s-shuman@ski.mskcc.org, limac@mskcc.org Article published online ahead of print. Article and publication date are at http://www.rnajournal.org/cgi/doi/10.1261/rna.050286.115.
The principal CTD serine phosphatase is Fcp1 (Chambers and Dahmus 1994; Chambers and Kane 1996; Archambault et al. 1997; Cho et al. 1999; Kobor et al. 1999). Fcp1 is conserved among eukarya and is essential for cell viability in budding and fission yeast (Archambault et al. 1997; Kimura et al. 2002) and for Drosophila development (Tombácz et al. 2009). A partial deficiency of human Fcp1 underlies an autosomal recessive developmental disorder (Varon et al. 2003).

Schizosaccharomyces pombe Fcp1 (SpFcp1), a 723-aa monomeric protein, is a prototype of the Fcp1 family. SpFcp1 catalyzes metal-dependent hydrolysis of either Ser2- $\mathrm{PO}_{4}$ or Ser5$\mathrm{PO}_{4}$ CTD substrates, but displays a preference for Ser2- $\mathrm{PO}_{4}$ (Hausmann and Shuman 2002). The minimal effective CTD substrate for SpFcp1 is a single heptad of phasing SPSYS $_{2 \mathrm{P}} \mathrm{PT}$. The Tyr1 and Pro3 side chains that flank the Ser2- $-\mathrm{PO}_{4}$ mark are important determinants of SpFcp1 activity (Hausmann et al. 2004). Deletion analysis has defined the

(c) 2015 Schwer et al. This article is distributed exclusively by the RNA Society for the first 12 months after the full-issue publication date (see http:// rnajournal.cshlp.org/site/misc/terms.xhtml). After 12 months, it is available under a Creative Commons License (Attribution-NonCommercial 4.0 International), as described at http://creativecommons.org/licenses/by-nc/4.0/. 
central segment, SpFcp1-(140-580), as sufficient for phosphatase activity in vitro (Hausmann and Shuman 2003). Mutational analysis of SpFcp1 identified the essential active site constituents (Hausmann and Shuman 2002, 2003; Hausmann et al. 2004) and established SpFcp1 as a member of the DxDxT superfamily of phosphotransferases (Burroughs et al. 2006) that form a covalent enzyme-(aspartyl-O $\delta$-)-phosphate intermediate at the first Asp of the DxDxT motif (Fig. 1).

The crystal structure of SpFcp1-(140-580) revealed a Y-shaped globular protein in which the acyl-phosphatase (FCPH) domain is situated at the base of the Y (Fig. 1A; Ghosh et al. 2008). An a helical module inserted into the FCPH domain comprises the left arm of the Y. The right arm of the $\mathrm{Y}$ is a BRCT domain. The phosphatase active site is located within the FCPH domain at the base of a deep canyon, the sides of which are formed by the helical insert and BRCT modules (Fig. 1A). It is proposed that the CTD threads through the SpFcpl canyon to access the active site (Ghosh et al. 2008).

Fcp1 is a pan-eukaryal CTD phosphatase that plays an essential role in Pol 2 transcription. Its essentiality is likely linked to dephosphorylation of Pol2 (Fuda et al. 2012), but there are key unresolved questions, including the following: (i) Is Fcp1's essentiality in vivo tied to its action at a specific CTD phosphate mark, e.g., Ser2- $\mathrm{PO}_{4}$ versus Ser5- $\mathrm{PO}_{4}$ ? (ii) Do Fcp1 enzymes dephosphorylate other proteins? (iii) Does an Fcp1 catalytic domain suffice for function in vivo? (iv) Do the non- catalytic amino-terminal and carboxy-terminal segments of Fcp1 contribute to its essential function?

Here we address these issues genetically in the fission yeast S. pombe, taking advantage of a collection of biochemically characterized SpFcp1 mutants, including structure-guided mutations of "gatekeeper" residues that alter the Ser2/Ser5 substrate selectivity in vitro (Ghosh et al. 2008). We also exploit S. pombe Rpb1 mutants (Schneider et al. 2010; Schwer and Shuman 2011; Schwer et al. 2014) to illuminate genetic interactions between SpFcp1 activity and CTD composition. We conduct a new mutational analysis of the noncatalytic $\mathrm{N}$ domain of SpFcp1, which we show is essential in vivo. We report that SpFcp1 acts as a threonine phosphatase at the CTD of the fission yeast transcription elongation factor Spt5. In addition, we report a new atomic structure of SpFcp1 that illuminates the transition state of the aspartyl-phosphoenzyme hydrolysis reaction.

\section{RESULTS}

\section{Phosphatase activity of SpFcp1 is essential in vivo}

As it now stands, the genetics of $S$. pombe Fcp1 are limited to the following two points: (i) Deletion of the $S$. pombe $f_{c p} 1^{+}$ gene is lethal (Kimura et al. 2002); and (ii) screening of a fission yeast ts mutant library for conditional loss of viability upon entering quiescence (by nitrogen starvation) yielded
A

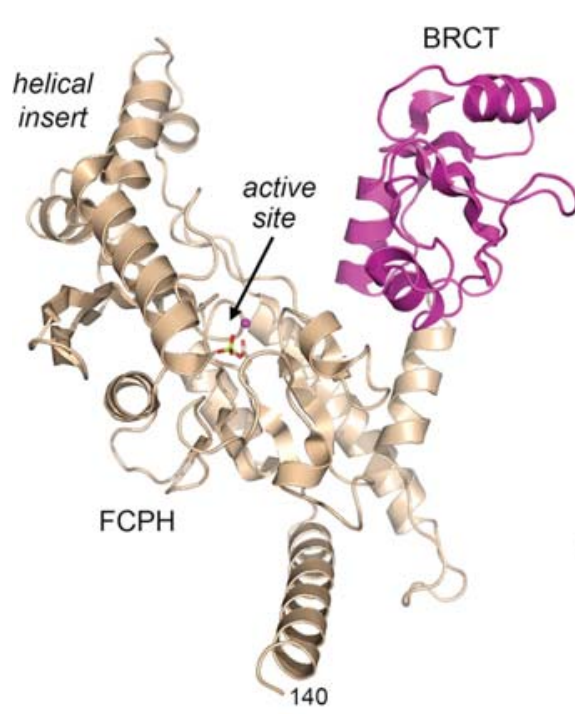

B

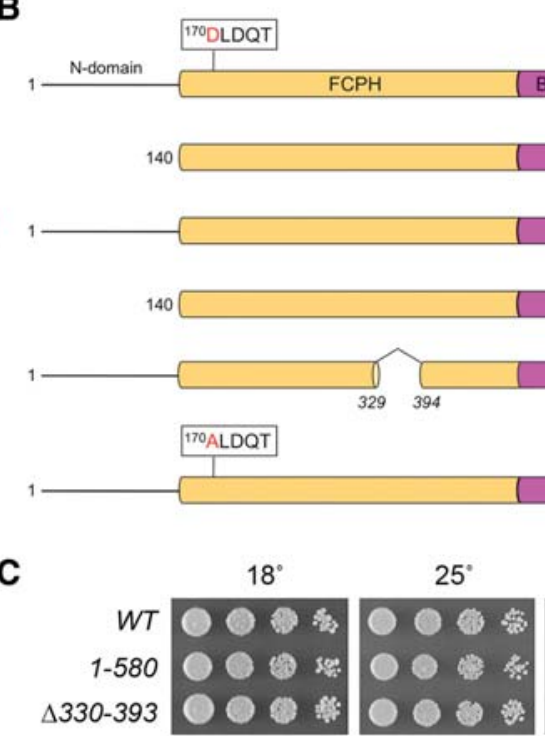

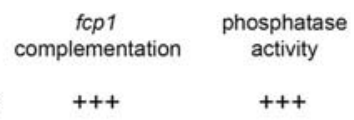
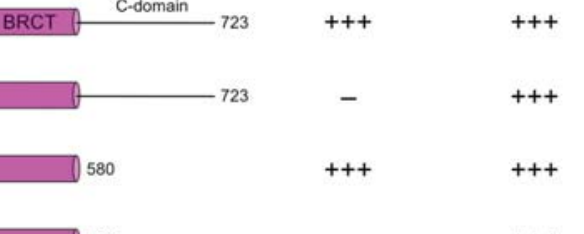

$-$

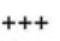

$+++$

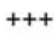

FIGURE 1. Requirements for SpFcpl activity in vivo. (A) Tertiary structure of SpFcp1(140-580) from pdb 3EF1. The core catalytic FCPH module sits at the base of the $Y$-shaped protein. The left prong of the $\mathrm{Y}$ is formed by a helical module inserted into the FCPH domain; the right prong is a BRCT domain (magenta). The active site (arrow) is demarcated by a $\mathrm{Mg}^{2+}$ ion (magenta sphere) and Asp170-BeF 3 adduct (stick model). (B) Cartoon representations of the wild-type and mutated Fcp1 proteins. The FCPH and BRCT modules within the central catalytic domain are denoted as beige and magenta cylinders. The position of the signature DxDxT motif of the acyl-phosphatase superfamily is highlighted. The flanking $\mathrm{N}$ and $\mathrm{C}$ domains are horizontal lines. The column at right indicates whether the respective recombinant Fcpl proteins have phosphatase activity in vitro. The column at left indicates whether the $f_{c p} 1$ alleles encoding the indicated proteins are functional in vivo in $S$. pombe. Lethal alleles are indicated by -. $(C)$ Exponentially growing cultures of $S$. pombe strains with the indicated chromosomal $f_{c p} 1$ alleles were adjusted to $A_{600}$ of 0.1 and aliquots of serial fivefold dilutions were spotted to YES agar and incubated at the indicated temperatures. 
an $f c p 1$-ts allele with a single $R 223 \mathrm{~K}$ coding change (Sajiki et al. 2009). The latter finding reveals an intriguing phenotype, but is not mechanistically informative, insofar as the SpFcp1 R223K mutant is severely defective as a phosphatase in vitro (Hausmann and Shuman 2003) and the crystal structure teaches that Arg223 is not a catalytic residue, but plays a structural role in tethering the active site ${ }^{170} \mathrm{DxDxT}$ loop to surrounding secondary structure elements (Ghosh et al. 2008). Our aim here was to query genetically the essential functions of SpFcp1. To do so, we established a complementation assay by allelic exchange at the chromosomal $f c p 1$ locus. Wild-type and mutant $f_{c p} 1$ integration cassettes (marked with hygMX $3^{\prime}$ of the ORF) were exchanged by homologous recombination for one of the chromosomal $f c p 1^{+}$alleles in a diploid strain of $S$. pombe. The correct integrations were verified by diagnostic PCR and by sequencing to ensure that the entire $f c p 1$ sequence was incorporated at the $f c p 1$ locus of hygromycinresistant diploids. The diploids were sporulated at $30^{\circ} \mathrm{C}$ and large numbers $(\geq 1000)$ of viable haploid progeny were scored for the presence of the $h y g M X$ gene linked to the $f c p 1$ locus. Failure to recover any viable hygromycin-resistant haploids signified that the pertinent $f_{c p} 1$ allele was lethal. When viable haploids were obtained, we resequenced the $f c p 1$ locus to confirm that the entire mutated ORF was encoded and that no unwanted changes or partial allelic exchanges (e.g., by crossing over within the fcp 1 ORF) had occurred.

We used this assay to ask and answer two key questions: (i) Is the phosphatase activity of SpFcp1 essential for S. pombe viability? [YES]; and (ii) does catalytic activity suffice for SpFcp1 function in vivo? [NO]. The essentiality of phosphatase activity was established by the lethality of $f c p 1-D 170 \mathrm{~A}$ (Fig. 1B), which encodes a catalytically inert SpFcp1 protein (Hausmann and Shuman 2002). However, phosphatase activity was not sufficient for SpFcp1 function, given the lethality of $f c p 1-(140-580)$ (Fig. 1), which encodes the central FCPH+BRCT domain that has full phosphatase activity in vitro (Hausmann and Shuman 2003).

\section{The noncatalytic $\mathbf{N}$ domain of SpFcp1 is essential in vivo}

By singly deleting the amino-terminal and carboxy-terminal segments flanking the catalytic domain, we found that the $\mathrm{N}$ domain (aa 1-139) was essential for SpFcp1 function in vivo, whereas the $\mathrm{C}$ domain (aa 581-723) was dispensable (Fig. 1B,C). Indeed, the $f c p 1-(1-580)$ strain grew as well as wild-type yeast on YES agar medium at $18^{\circ} \mathrm{C}-34^{\circ} \mathrm{C}$ (Fig. $1 \mathrm{~B}$, scored as +++ growth based on colony size), while forming slightly smaller colonies at $37^{\circ} \mathrm{C}$ (Fig. $1 \mathrm{C}$ ). In contrast, the equivalent $\mathrm{N}$ and $\mathrm{C}$ domains of S. cerevisiae $\mathrm{Fcp} 1$ are both dispensable, though their simultaneous deletion is lethal (Kobor et al. 2000).

The initial crystal structure of the SpFcp1 catalytic domain highlighted a disordered 70-aa segment within the FCPH module, from aa 327-396. Previously, we produced and pu- rified an internal deletion mutant of the SpFcp1 catalytic domain, SpFcp1-(149-580)- $\Delta 330-393$, in which amino acids 330-393 were removed and the two flanking segments (aa 149-329 and 394-580) were fused. The purified recombinant SpFcp1-(149-580)- $\Delta 330-393$ protein retained full phosphatase activity in vitro for Ser2- $\mathrm{PO}_{4}$ and Ser5- $\mathrm{PO}_{4}$ CTD substrates (Ghosh et al. 2008). Here we tested the inter-

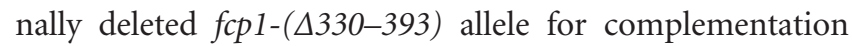
and found that it supported wild-type growth at all temperatures tested (Fig. 1B,C).

\section{Mutational analysis of the $\mathrm{N}$ domain of SpFcp1}

We conducted a phylogenetic-guided mutational analysis of the essential $\mathrm{N}$ domain of SpFcp1. The primary structures of the $\mathrm{N}$ domains of $S$. pombe, Candida albicans, and Aspergillus fumigatus $\mathrm{Fcp} 1$ are aligned in Figure 2A, with 52 positions of side chain identity/similarity indicated by a circle $(\bullet)$. Our initial efforts to delineate a minimally functional domain entailed testing complementation of $f c p 1 \Delta$ by alleles with serial amino-terminal deletions of 20,40 , or 60 amino acids. The $f c p 1-(21-723), f_{c p} 1-(41-723)$, and $f c p 1-(61-723)$ alleles were uniformly lethal, suggesting that the full $\mathrm{N}$ domain is necessary for SpFcp1 function in vivo.

To our inspection, the distinctive feature of the $\mathrm{N}$ domain is a ${ }^{99} \mathrm{CxH} x x x x x x x C x \mathrm{C}^{112}$ motif (bracketed in Fig. $2 \mathrm{~A}$ ), which is widely conserved among Fcpl homologs from diverse taxa (including human Fcp1), and is a likely metalbinding module. Our initial test of this idea entailed complementation of $f_{c p} 1 \Delta$ by two double-alanine mutant alleles, C99A-H101A and C109A-C112A, that should compromise metal binding. Indeed we found that both of these alanine cluster mutations were lethal in vivo. We then tested complementation by single alanine mutants and found that $C 99 A$, H101A, C109A, and C112A were all lethal (Fig. 2B). We conclude that the putative metal-binding site is essential for SpFcpl function in vivo.

In addition, we tested the effects of alanine changes at 10 other conserved basic, acidic, or polar residues on $f c p 1$ complementation: Lys33, Glu67, Glu71, Glu73, Glu97, Asn104, Tyr105, Lys114, Arg129, and His136 (denoted by $\mathbf{\nabla}$ in Fig. 2A). Nine of the fcp1-Ala alleles supported wild-type fission yeast growth at all temperatures tested (scored as +++ growth in Fig. 2B). The lone outlier was the $f c p 1-Y 105 A$ strain, which was viable but sick, forming tiny colonies on rich agar medium (scored as + growth in Fig. 2B). Tyr105 is situated in the loop segment between the pairs of putative zinc ligands (Fig. 2A).

\section{SpFcp1 phosphatase essentiality is not bypassed by eliminating its preferred CTD Ser2 target}

$\mathrm{SpFcpl}$ is four- to tenfold more active in vitro in dephosphorylating Ser2- $-\mathrm{PO}_{4}$ versus Ser5- $\mathrm{PO}_{4}$ CTD substrates (Hausmann and Shuman 2002; Ghosh et al. 2008). A phosphomimetic glutamate substitution for Ser2 in every consensus 
A

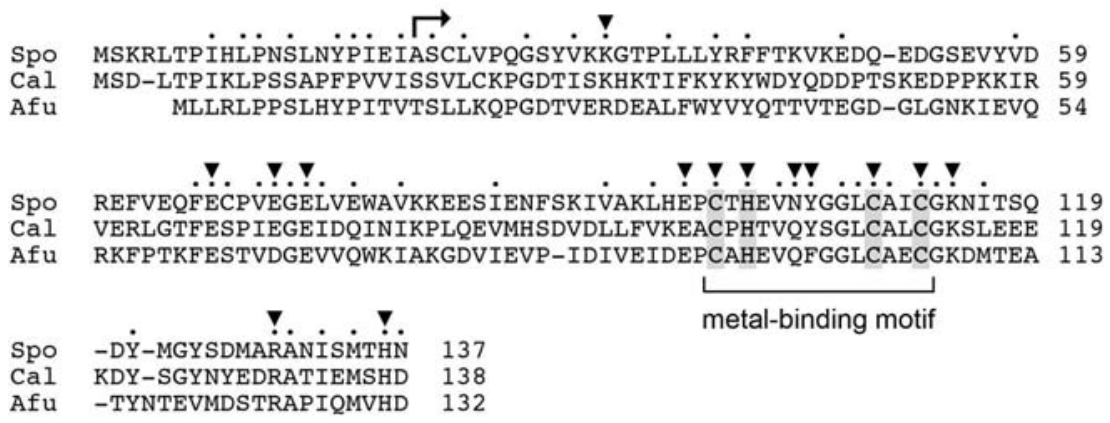

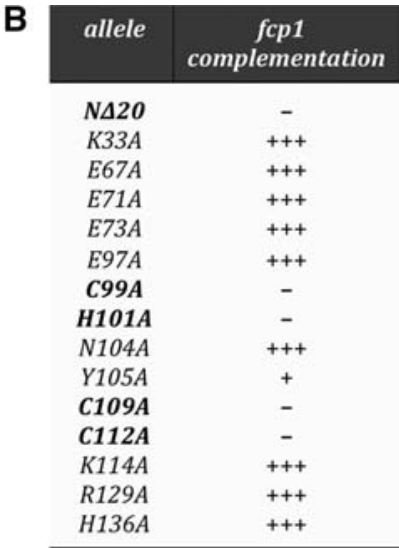

FIGURE 2. Mutational analysis of the essential N domain. (A) Alignment of the primary structures of the Fcp1 N domains of Schizosaccharomyces pombe (Spo), Candida albicans (Cal), and Aspergillus fumigatus (Afu). Positions of amino acid side chain identity/similarity in all three proteins are indicated by $\bullet$. Conserved residues targeted for alanine scanning in SpFcpl are denoted by $\mathbf{\nabla}$. A putative CHCC metal-binding motif is demarcated by a bracket. The lethal $\Delta 20$ truncation is denoted by $r$. (B) The indicated $f_{c p} 1$ alleles were tested for complementation in vivo. Lethal alleles are denoted by.-+++ Indicates growth on YES agar indistinguishable from wild-type $f c p 1^{+}$. Y105A cells grew slowly (scored as + ) and formed tiny colonies on YES agar.

CTD heptad is lethal in vivo (Schwer and Shuman 2011). If it is the case that removal of the Ser2- $\mathrm{PO}_{4}$ mark is the singular essential function of SpFcp 1 in vivo, then the lethality of the phosphatase-dead $f_{c p} 1-D 170 A$ allele might be rescued if there were no Ser2- $\mathrm{PO}_{4}$ marks to erase. Putting this thought experiment to the test is feasible in fission yeast, because $S$. pombe is viable when all of the Ser2 positions in the consensus CTD heptad repeat array are replaced by alanine (Schwer and Shuman 2011). We found that $f_{c p} 1-$ $D 170 A$ remained lethal in the $r p b 1-C T D-S 2 A$ genetic background, signifying that Ser2- $\mathrm{PO}_{4}$ is not the sole essential target of SpFcp1.

Ser5 is the only phospho-acceptor amino acid in the Pol2 CTD that is strictly essential for growth of fission yeast (Schwer and Shuman 2011). Replacing all of the Ser5 residues in the consensus heptads with alanine is lethal because the Ser5- $\mathrm{PO}_{4}$ mark is needed for recruitment of the fission yeast mRNA capping enzymes RNA triphosphatase and RNA guanylyltransferase to the Pol2 elongation complex (Pei et al. 2001; Doamekpor et al. 2014). The lethality of rpb1-CTD$S 5 A$ can be rescued by covalently fusing mammalian capping enzyme (MCE, a bifunctional RNA triphosphatase-guanylyltransferase) to the mutant Rpb1-S5A polypeptide (Schwer and Shuman 2011). Here we found that the phosphatase-defective $f_{c p 1-D 170 A}$ allele remained lethal in the rpb1-CTD$S 5 A-M C E$ genetic background, from which we infer that Ser5- $\mathrm{PO}_{4}$ is not the sole essential target of SpFcp1.

\section{SpFcp1 substrate 'gatekeeper' mutations R271A and R299A are lethal in vivo}

Guided by the SpFcp1 crystal structure, we previously sought to identify determinants of substrate specificity by introducing mutations of amino acids that either mediate contacts be- tween the FCPH core and the helical insert (e.g., Arg271) or line the surface of the canyon (e.g., Arg299, Trp305, Val313, Pro314, Trp516). Recombinant mutant SpFcp1-(140-580) proteins were assayed for phosphatase activity with tri-heptad CTD substrates phosphorylated uniquely at Ser2 or Ser5 of each heptad. By testing both substrates in parallel, we identified biased specificity phenotypes in the cases of the R271A, R299A, and W516S mutations, which suppressed Ser5 phosphatase activity but had relatively modest effects on Ser2 phosphatase activity (Ghosh et al. 2008). These mutations skewed the Ser2/Ser5 activity ratio such that R271A, R299A, and W516S had greater preferences for Ser2- $\mathrm{PO}_{4}$ than did wild-type Fcp1. We proposed that Arg271, Arg299, and Trp516 can act as gatekeepers of SpFcp1 substrate choice, i.e., they are permissive for Ser5- $\mathrm{PO}_{4}$ when present and restrictive when removed. In an initial attempt to gain a genetic correlate to the biochemical effects of an Ser2/Ser5 activity skew, we introduced the equivalent mutations into $S$. cerevisiae Fcp1 (R298A, R326A, and W529S) and tested them by plasmid shuffle for complementation of a lethal $S$. cerevisiae $f c p 1 \Delta$ mutant, finding that these three ScFcp1 mutations had no apparent effect on $S$. cerevisiae growth at any temperature tested (Ghosh et al. 2008). However, in light of the significant differences in the genetic requirements for Fcp1 domains in fission yeast versus budding yeast, and the differences in CTD structure-activity relations in these two yeast taxa, we elected to genetically test the effects of the SpFcp1 gatekeeper mutations in S. pombe.

The salient findings were that the R271A and R299A alleles were lethal in $S$. pombe, whereas a W516S strain was viable and grew normally at all temperatures (Fig. 3A). Several other mutations at the SpFcp1 canyon surface also had no impact on fission yeast growth: W305S, V313D, and P314D (Fig. 3A). 


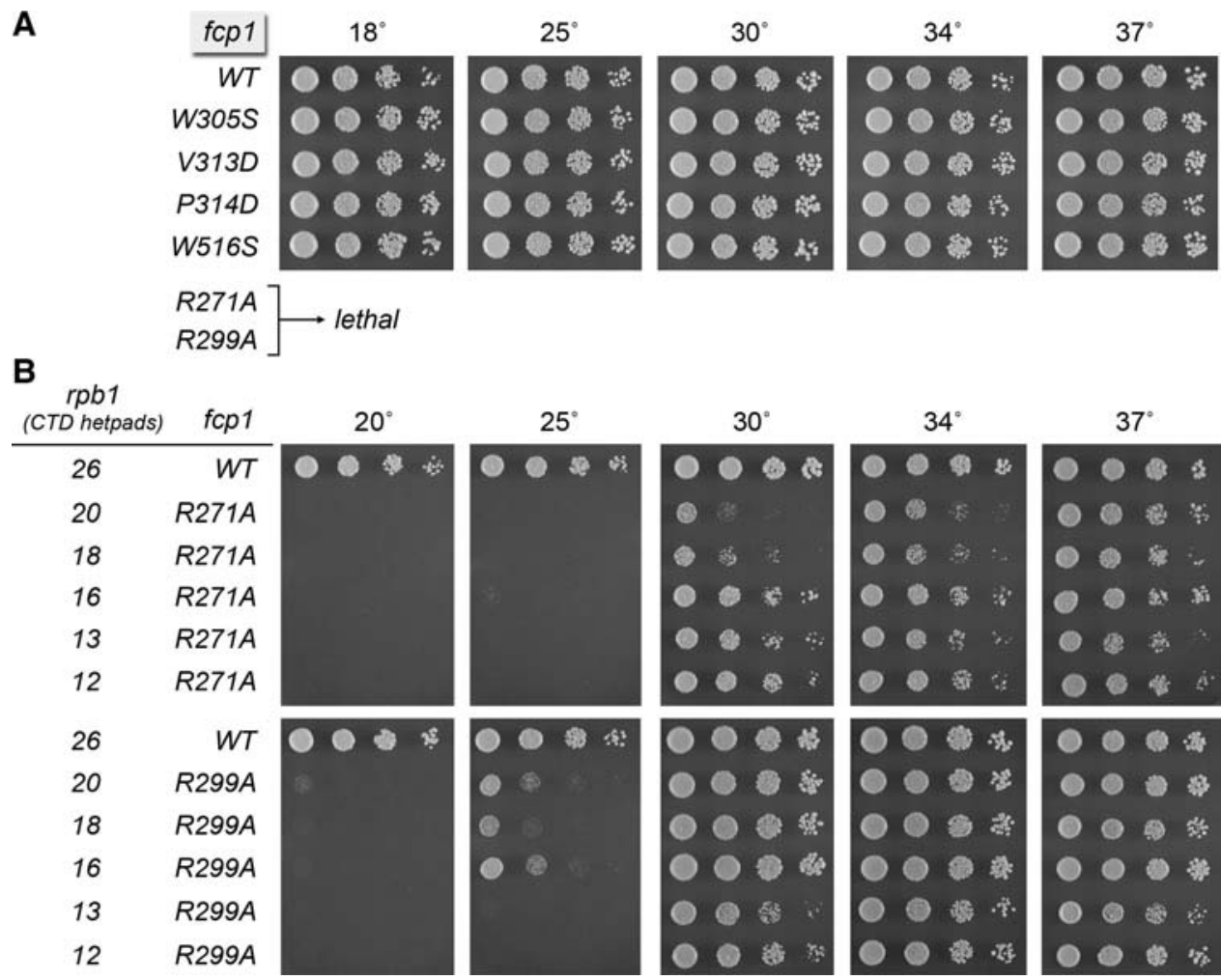

FIGURE 3. Lethality of gatekeeper mutations R271A and R299A is rescued by CTD shortening. (A) Exponentially growing cultures of S. pombe strains with the indicated chromosomal $f_{c p} 1$ alleles were adjusted to $A_{600}$ of 0.1 and aliquots of serial fivefold dilutions were spotted to YES agar and incubated at the indicated temperatures. The R271A and $R 99 A$ alleles were lethal in an $r p b 1^{+}$genetic background. (B) rpb1-natMX cassettes in which the Pol2 CTD was serially truncated from the C terminus to reduce the number of repeats to $26,20,18,16,13$, or 12 were exchanged at the $r p b 1$ locus of heterozygous $f c p 1^{+}, f c p 1-R 271 A-h y g M X$, and $f c p 1-R 299 A-h y g M X$ diploid strains. hyg ${ }^{\mathrm{R}}$ nat ${ }^{\mathrm{R}}$ haploids with the indicated genotypes were recovered after sporulation, revealing that CTD truncation to $\leq 20$ repeats rescued the lethality of $R 271 A$ and $R 299 A$. Serial dilutions of exponentially growing yeast cultures as specified were spotted to YES agar and incubated at the indicated temperatures.

\section{Shortening the CTD repeat array rescues lethality of fcp1-R271A and fCp1-R299A}

The lethality of the $f c p 1-R 271 A$ and $f c p 1-R 299 A$ alleles was observed in an $r p b 1^{+}$strain that expresses the native wild-type fission yeast Pol2 CTD, which consists of 25 YSPTSPS repeats connected to the body of the Rpb1 subunit via 4 degenerate repeats (the CTD "rump") that deviate in size and/or sequence from the consensus heptad. Because the R271A and R299A SpFcp1 mutants are biochemically hypomorphs, we considered that they might regain biological activity if the dephosphorylation "workload" were lessened. To test this idea, we exploited a set of fission yeast strains with chromosomal rpb1 alleles encoding CTDs serially truncated at their carboxy-termini so as to comprise $26,20,18,16,13$, or 12 repeats (i.e., the rump plus $22,16,14,12$, 9, or 8 consensus heptads) (Schneider et al. 2010). Whereas $f c p 1-R 271 A$ and $f c p 1-$ $R 299 A$ remained lethal in the rpb1-26 background, shortening the CTD to 20 repeats or fewer permitted complementation by $R 271 A$ and $R 299 A$ (Fig. 3B). In a wild-type $f_{c p} 1^{+}$ background, the rpb1-20, rpb1-18, and rpb1-16 strains grow as well as $r p b 1-26$ at all temperatures; $f c p 1^{+} \quad r p b 1-13$ and $f_{c p} 1^{+} r p b 1-12$ strains are cold-sensitive (Schneider et al.
2010). Here we found that $f c p 1-R 299 A$ supported vigorous growth at $30^{\circ} \mathrm{C}, 34^{\circ} \mathrm{C}$, and $37^{\circ} \mathrm{C}$ with a CTD having 20,18 , or 16 repeats, while displaying a tight cold-sensitive growth defect, seen as slow growth at $25^{\circ} \mathrm{C}$ and no growth at $20^{\circ} \mathrm{C}$ (Fig. 3B). $f c p 1-R 271 A$ had a more pronounced cold-sensitive defect in the context of 20,18 , or 16 repeats (e.g., no growth at $25^{\circ} \mathrm{C}$ ) and displayed a serial improvement in growth at $30^{\circ} \mathrm{C}$ as the CTD was shortened from 20 to 16 repeats (Fig. 3B). Our inference from these results is that downward titration of SpFcp1 phosphatase activity by certain hypomorphic mutations can be compensated in vivo (at least at higher temperatures) by reducing CTD length, and hence the number of potential phosphorylation marks.

\section{Synthetic genetic interaction of Fcp1 mutations with Ssu72 null and phosphatase-dead mutants}

The CTD phosphatase Ssu72 is an agent of Ser5 dephosphorylation in the budding yeast Saccharomyces cerevisiae (Krishnamurthy et al. 2004; Hausmann et al. 2005). Ssu72 catalyzes phosphoryl transfer via a covalent enzyme-cysteinyl-S-phosphate intermediate (Zhang et al. 2011); mutation of the active 
site cysteine to serine or alanine abolishes phosphatase activity. The Ssu72 protein and its phosphatase activity are essential for the viability of S. cerevisiae (Krishnamurthy et al. 2004). In contrast, $S$. pombe Ssu72 is dispensable for growth of fission yeast (Schwer et al. 2012). We considered the possibility that partial functional overlap between SpFcp1 and Ssu72 might mask potential effects of hypomorphic SpFcp1 mutations on fission yeast growth. To test this idea, we introduced $f_{c p} 1$ alleles V313D, P314D, W305S, and 1-580 into ssu72 ${ }^{+}$, ssu72 , and ssu72-C13S cells that expressed wild-type Ssu72, no Ssu72, and a catalytically dead Ssu72, respectively. Spot tests of growth on YES agar revealed mutational synergies of canyon surface mutations P314D and W305S (but not V313D) in the ssu $72 \Delta$ and ssu72-C13S genetic backgrounds, evinced by inability to grow at $37^{\circ} \mathrm{C}$ and slow growth at $34^{\circ} \mathrm{C}$ (Fig. 4). Deletion of the SpFcp1 C domain elicited the same synthetic ts growth defect when Ssu72 was inactivated (Fig. 4).

\section{SpFcp1 dephosphorylates Thr1 of the Spt5 CTD}

Transcription elongation factor Spt5 is a large polypeptide, composed of multiple domain modules, that associates with the Pol2 transcription complex shortly after initiation and can exert negative and positive effects on transcription elongation (Hartzog and Fu 2013). Fission yeast Spt5 has a distinctive carboxy-terminal repeat domain (the "Spt5 CTD"), composed of 18 repeats of a nonapeptide motif $\left(\mathrm{T}^{1} \mathrm{P}^{2} \mathrm{~A}^{3} \mathrm{~W}^{4} \mathrm{~N}^{5} \mathrm{~S}^{6} \mathrm{G}^{7} \mathrm{~S}^{8} \mathrm{~K}^{9}\right.$ ), that (i) binds the fission yeast RNA capping enzymes RNA triphosphatase and RNA guanylyltransferase (Pei and Shuman 2002), and (ii) is targeted for threonine phosphorylation by the Cdk9 kinase (Pei and Shuman 2002, 2003; Viladevall et al. 2009). The CTDs of fis- sion yeast Pol2 and Spt5 play overlapping roles in recruiting the capping enzymes in vivo (Schneider et al. 2010). Unlike the capping enzyme-Pol2-CTD interactions, which stringently depend on the Ser5- $\mathrm{PO}_{4}$ mark, binding of fission yeast triphosphatase and guanylyltransferase to the Spt5 CTD is independent of Thr1 phosphorylation (Pei et al. 2001; Pei and Shuman 2002). Indeed, their binding to the Spt5 CTD is antagonized by Thr1 phosphorylation (Doamekpor et al. 2014, 2015). The phosphatase(s) responsible for removing the $\mathrm{Thr} 1-\mathrm{PO}_{4}$ mark from the Spt5 CTD have not been defined.

Here we evaluated the ability of purified recombinant SpFcp1-(140-580) to act as an Spt5 CTD phosphatase. The substrate used was a 22-aa long synthetic peptide (SGSKT $\left._{1 \mathrm{P}} \mathrm{PAWNSGSKT}_{1 \mathrm{P}} \mathrm{PAWNSGSK}\right)$ in which both Thrl residues were phosphorylated. The enzyme was assayed in parallel for Pol2 CTD Ser2 and Ser5 phosphatase activities, using 28-aa synthetic peptides, comprising four tandem $\mathrm{YS}_{2 \mathrm{P}} \mathrm{PTSPS}$ or $\mathrm{YSPTS}_{5 \mathrm{P}} \mathrm{PS}$ repeats. Increasing concentrations of SpFcpl were reacted with $25 \mu \mathrm{M}$ of the Pol2 CTD peptides or $50 \mu \mathrm{M}$ Spt5 CTD peptide (to achieve the same concentration of $100 \mu \mathrm{M}$ total phosphoamino acid) for $45 \mathrm{~min}$ at $37^{\circ} \mathrm{C}$ and release of inorganic phosphate was quantified colorimetrically. Product was divided by reaction time and the values were plotted as a function of Fcpl concentration (Fig. 5A). Turnover numbers were calculated from the slopes of the titration curves (Fig. 5A). SpFcp1 was several-fold more active as a Pol2 CTD phosphatase at Ser2- $\mathrm{PO}_{4}(0.13 \pm 0.005$ $\left.s^{-1}\right)$ than Ser5- $\mathrm{PO}_{4}\left(0.042 \pm 0.002 \mathrm{~s}^{-1}\right)$. The instructive finding was that SpFcp1 also hydrolyzed Spt5 CTD-Thr1-PO $\left(0.016 \pm 0.001 \mathrm{~s}^{-1}\right)$, albeit one-third as well as it hydrolyzed Pol2 CTD-Ser5- $\mathrm{PO}_{4}$. Mutating the SpFcp1 active site

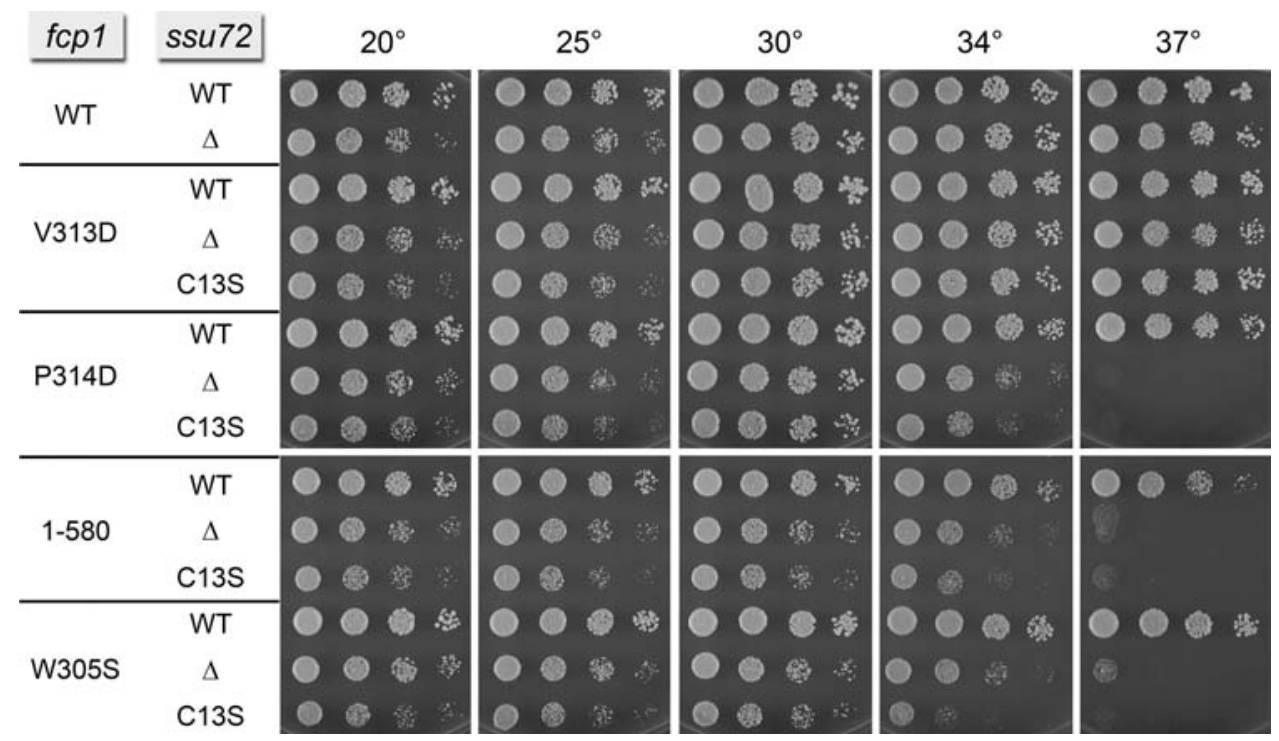

FIGURE 4. Synthetic genetic interaction of Fcp1 mutations with null mutants of Ssu72. Haploid $f c p 1-h y g M X$ strains were mixed with $s s u 72^{+}-k a n M X$ (WT), ssu72::kanMX $(\Delta)$, or ssu72-(C13S)-kanMX strains (Schwer et al. 2012) of the opposite mating type on malt agar for mating and sporulation, after which hyg ${ }^{\mathrm{R}} \mathrm{kan}^{\mathrm{R}}$ haploids with the indicated genotypes were recovered. Exponentially growing cultures of the strains specified were adjusted to $A_{600}$ of 0.1 and aliquots of serial fivefold dilutions were spotted to YES agar and incubated at the indicated temperatures. 

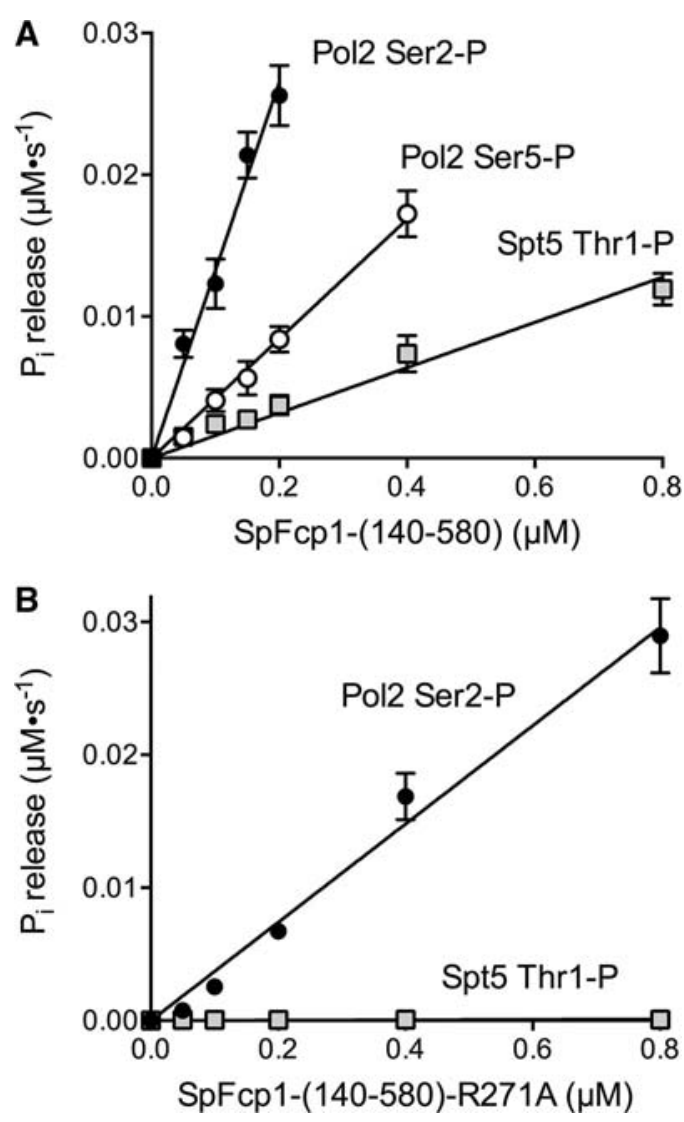

FIGURE 5. Spt5 CTD threonine phosphatase activity of SpFcp1. (A) Phosphatase activity of SpFcp1-(140-580) with the indicated Pol2 CTD Ser2 $-\mathrm{PO}_{4}$, Ser5- $-\mathrm{PO}_{4}$, or Spt5 CTD Thr1- $\mathrm{PO}_{4}$ peptide substrates was assayed as described in Materials and Methods. Phosphate release (normalized to reaction time) is plotted as a function of input SpFcp1-(140-580) concentration. (B) Phosphatase activity of SpFcp1(140-580)-R271A with the Pol2 CTD Ser2-PO ${ }_{4}$ and Spt5 CTD Thr1$\mathrm{PO}_{4}$ peptide substrates is plotted as a function of enzyme concentration. Each datum in the graphs is the average of three independent experiments (that were each performed in triplicate) \pm SEM. The data were fit by linear regression in Prism.

nucleophile Asp170 to asparagine abolished CTD Thr1- $\mathrm{PO}_{4}$ hydrolysis (data not shown), affirming that the threonine phosphatase activity inhered to SpFcp1.

\section{Arg271 enables Spt5 CTD threonine phosphatase activity}

In light of earlier findings that Arg271 influences Pol2 CTD substrate preference (Ghosh et al. 2008) we queried the impact of the R271A mutation on hydrolysis of Pol2 CTD-Ser2$\mathrm{PO}_{4}$ versus Spt5 CTD-Thr1- $\mathrm{PO}_{4}$ (Fig. 5B). The turnover number of R271A as Ser2 phosphatase $\left(0.037 \pm 0.002 \mathrm{~s}^{-1}\right)$ was about threefold lower than wild-type SpFcp1, a modest decrement. In contrast, the R271A protein was inert as an Spt5 CTD Thr1 phosphatase (Fig. 5B). These results fortify the role of Arg271 as a gatekeeper of substrate choice, whereby SpFcp1 acts on Spt5 as a CTD Thr1 phosphatase when
Arg271 is present, but is limited to its Pol2 CTD Ser2 phosphatase activity when Arg271 is absent.

\section{Crystal structures of the R271A phosphatase illuminate the Fcp1 reaction mechanism}

SpFcp1 remodels the CTD by a two-step ping-pong reaction involving formation and hydrolysis of a phospho-enzyme intermediate. In the first step, the Asp170 O $\delta$ acts as the nucleophile to attack the phosphorus atom of the CTD phosphoserine, resulting in formation of an acyl-phosphate intermediate and expulsion of the dephosphorylated CTD product. In the second step, a water nucleophile attacks the acyl-phosphate, resulting in formation of the inorganic phosphate product and expulsion of Asp170. Previous efforts to crystallize SpFcp1 bound to a CTD peptide were unsuccessful, conceivably because $\mathrm{SpFcp} 1$ can recognize either Ser2 or Ser5 as its target. Here we revisited the problem with the R271A mutant, which has enhanced selectivity for Ser2. We premixed purified recombinant SpFcp1-(149-580)- $\Delta 330-393-$ (R271A) protein with $\mathrm{AlCl}_{3}, \mathrm{NaF}, \mathrm{MgCl}_{2}$ and CTD peptide SPSYSPTSPS in an attempt to capture an enzyme- $\mathrm{AlF}_{3}$-peptide complex as a mimetic of the transition state of the first phosphoryl transfer step. A crystal grown by sitting drop vapor diffusion at pH 6.5 diffracted X-rays to $1.45 \AA$ resolution. The structure was solved by molecular replacement and refined to $R_{\text {work }} / R_{\text {free }}$ of $15.4 / 18.2$ (see Table 1 ).

The instructive crystallographic findings pertained to the occupancy of the active site by a single $\mathrm{Mg}^{2+}$ ion and a trigonal planar $\mathrm{AlF}_{3}$ adjacent to the Asp170 nucleophile. We detected no electron density for a CTD peptide on the face of the planar $\mathrm{AlF}_{3}$ opposite Asp170. Rather, this site was occupied by a water molecule that we propose corresponds to the nucleophile in the second hydrolysis step of the Fcp1 reaction pathway. The trigonal planar $\mathrm{AlF}_{3}$ complex captured in this new structure (Fig. 6, bottom panel) is a more faithful mimetic of the transition state geometry than the square planar $\mathrm{AlF}_{4}^{-}$complex observed previously (Ghosh et al. 2008) and provides clearer insights to the reaction mechanism, as discussed in detail below.

We also grew crystals from a mixture of SpFcp1-(149580)- $\Delta 330-393-(\mathrm{R} 271 \mathrm{~A}), \mathrm{BeCl}_{3}, \mathrm{NaF}$, and $\mathrm{MgCl}_{2}$ that captured a covalent enzyme-aspartyl- $\mathrm{BeF}_{3}$ mimetic of the Michaelis complex of the aspartyl-phosphate hydrolysis reaction, the structure of which we solved at $1.85 \AA$ resolution (Table 1). This complex, with tetrahedral geometry at the beryllium atom (Fig. 6, top panel), exemplifies the precursor of the transition state. Adjacent to the Asp170- $\mathrm{BeF}_{3}$ adduct is an octahedrally coordinated $\mathrm{Mg}^{2+}$ ion. The six metal ligands are as follows: the main-chain carbonyl of Asp172; Asp170

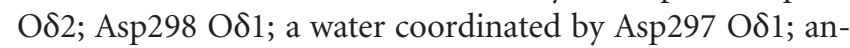
other water coordinated by Asp298 O 22 and Asp323 O 1 ; and a fluorine atom of $\mathrm{BeF}_{3}$, which mimics a phosphate oxygen (Fig. 6, top panel). The enzyme forms an oxyanion hole around the $\mathrm{BeF}_{3}$, whereby the fluorine atoms (mimicking the 
TABLE 1. Crystallographic data and refinement statistics

\begin{tabular}{|c|c|c|}
\hline & $\mathrm{SpFcp} 1 \cdot \mathrm{AlF}_{3}$ & SpFcp1--BeF 3 \\
\hline \multicolumn{3}{|l|}{ Data collection ${ }^{\mathrm{a}}$} \\
\hline Source & APS 24IDC & APS 24IDC \\
\hline Wavelength $(\AA)$ & 0.979 & 0.979 \\
\hline Number of crystals & 1 & 1 \\
\hline Space group & $\mathrm{P} 2{ }_{1} 2_{1} 2_{1}$ & $\mathrm{P} 2{ }_{1} 2_{1} 2_{1}$ \\
\hline \multicolumn{3}{|l|}{ Cell dimensions } \\
\hline$a, b, c(\AA)$ & $55.7,80.0,89.1$ & $55.4,80.2,89.2$ \\
\hline Resolution $(\AA)$ & $30-1.45(1.5-1.45)$ & $36.6-1.85$ (1.91-1.85) \\
\hline Completeness (\%) & $98.0(100.0)$ & $99.6(98.9)$ \\
\hline Total reflections & $472,393(46,049)$ & $163,342(16,068)$ \\
\hline Unique reflections & $70,713(6883)$ & $34,556(3027)$ \\
\hline Wilson B-factor & 15.1 & 21.7 \\
\hline Redundancy & $6.7(6.5)$ & $4.7(4.7)$ \\
\hline$R_{\text {merge }}(\%)$ & $5.3(62.2)$ & $6.1(58.4)$ \\
\hline $\mathrm{CC}_{1 / 2}(\%)$ & $99.9(84.8)$ & $99.9(84.1)$ \\
\hline $\mathrm{CC}^{*}(\%)$ & $100.0(95.8)$ & $100.0(95.6)$ \\
\hline$<I>/ \sigma(I)$ & $13.8(1.2)$ & $19.4(3.1)$ \\
\hline \multicolumn{3}{|l|}{ Refinement $^{\mathrm{a}}$} \\
\hline Resolution $(\AA ̊)$ & $20-1.45(1.5-1.45)$ & $36.6-1.85$ (1.91-1.85) \\
\hline Reflections: work/free & $66,517 / 3549$ & $32,886 / 3026$ \\
\hline$R_{\text {work }} / R_{\text {free }}(\%)$ & $15.4(24.9) / 18.2(27.4)$ & $15.8(23.7) / 20.1(27.4)$ \\
\hline Number of atoms & 3448 & 3196 \\
\hline Protein & 3022 & 2931 \\
\hline Ligand & 28 & 48 \\
\hline Water & 398 & 217 \\
\hline Average B-factors $\left(\AA^{2}\right)$ & 26.8 & 33.2 \\
\hline Protein & 25.1 & 32.5 \\
\hline Ligand & 44.7 & 58.5 \\
\hline Water & 38.5 & 37.6 \\
\hline \multicolumn{3}{|l|}{ RMSD } \\
\hline Bond lengths $(\AA)$ & 0.015 & 0.010 \\
\hline Bond angles $\left({ }^{\circ}\right)$ & 1.56 & 1.35 \\
\hline \multicolumn{3}{|l|}{ MolProbity ${ }^{b}$} \\
\hline Favored & $99.2 \%$ (377 aа) & $99.2 \%$ (364 aа) \\
\hline Allowed & $100 \%$ (380 аa) & $100 \%$ (367 aа) \\
\hline Outliers & None & None \\
\hline Clash score & 99th percentile & 100th percentile \\
\hline MolProbity score & 99th percentile & 100th percentile \\
\hline PDB ID Code & $4 \mathrm{XPZ}$ & $4 \mathrm{XQ0}$ \\
\hline
\end{tabular}

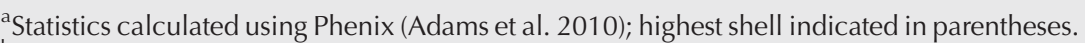
${ }^{b}$ Calculated with the program MolProbity (Chen et al. 2010).

virtually equidistant from the leaving Asp170 O $\delta(2.0 \AA)$ and the attacking water $(2.1 \AA)$. Note that the distance from the water to the phosphorus-like center is shortened in the $\mathrm{AlF}_{3}$ transition state complex compared with the $\mathrm{BeF}_{3}$ Michaelis complex (3.2 $\AA$ ), while the contact of the water nucleophile with the Asp172 general base is maintained. These structures provide evidence that Fcp1 catalyzes hydrolysis via an associative mechanism with a penta-coordinate phosphorane transition state. The octahedral magnesium complex is identical in the $\mathrm{BeF}_{3}$ and $\mathrm{AlF}_{3}$ structures, highlighting that the catalytic metal engages the same nonbridging phosphate oxygen in the transition as in the ground state. Lys280, Thr243, and the Leu171, Asp172, and Met244 main chain amides also contact the same nonbridging oxygens in the transition state as in the Michaelis complex.

\section{DISCUSSION}

The present study provides insights to the catalytic mechanism, substrate repertoire, and in vivo structure-activity relations of the essential fission yeast CTD phosphatase Fcp1. The chemistry of the aspartyl-phosphate hydrolysis step of the Fcpl pathway was clarified by comparison of new crystal structures of the catalytic domain, as an aspartyl- $\mathrm{BeF}_{3}$ "Michaelis complex" (1.85 $\AA$ ) and an $\mathrm{AlF}_{3}$ "transition state" (1.45 $\AA$ ). Beyond affording higher atomic resolution than previous $2.1 \AA$ SpFcpl structures, the new $\mathrm{AlF}_{3}$ structure captures the "correct"

nonbridging phosphate oxygens) are coordinated by Thr243 O $\gamma$, Lys $280 \mathrm{~N} \zeta$, and the main-chain amides of Leu171, Asp172, and Met244. Lys280 also contacts the bridging Asp170 O $\delta 1$ oxygen. The putative water nucleophile for the hydrolysis step is poised $3.2 \AA$ from the beryllium atom in an apical orientation to the bridging oxygen of Asp170 (water-Be-O $\delta 1$ angle of $171^{\circ}$ ). The water nucleophile is coordinated by the Asp172 side chain of the $\mathrm{DxD}^{172} \mathrm{xT}$ motif, which acts as a general base catalyst of the hydrolysis reaction.

In the structure of the transition state analog, the planar $\mathrm{AlF}_{3}$ is at the center of a trigonal bi-pyramidal coordination complex with Asp170 O $\delta$ at one apex and the attacking water at the other apical position (Fig. 6, bottom panel). The attacking water and the Asp 170 O $\delta$ leaving group subtend a $174^{\circ}$ angle about the aluminum center. The aluminum atom is trigonal bi-pyramidal geometry of the transition state, rather than the square bi-pyramidal configuration of the earlier $\mathrm{AlF}_{4}^{-}$ complex (Ghosh et al. 2008). The short bond distances from the aluminum center in $\mathrm{AlF}_{3}$ to the apically positioned attacking water and aspartyl-O $\delta$ leaving group weigh in favor of an associative mechanism of phosphoryl transfer by Fcp1, as has been observed for other members of the acylphosphatase superfamily (Wang et al. 2002; Lahiri et al. 2003; Lu et al. 2008; Daughtry et al. 2013). The $\mathrm{AlF}_{3}$ structure highlights the relative "quietness" of the active site during progression from Michaelis complex to hydrolytic transition state, whereby none of the enzymic or $\mathrm{Mg}^{2+}$ contacts to the scissile phosphate in the ground state are remodeled in the transition state. The outstanding structural issue for Fcp1 is its interaction with its phosphorylated CTD 

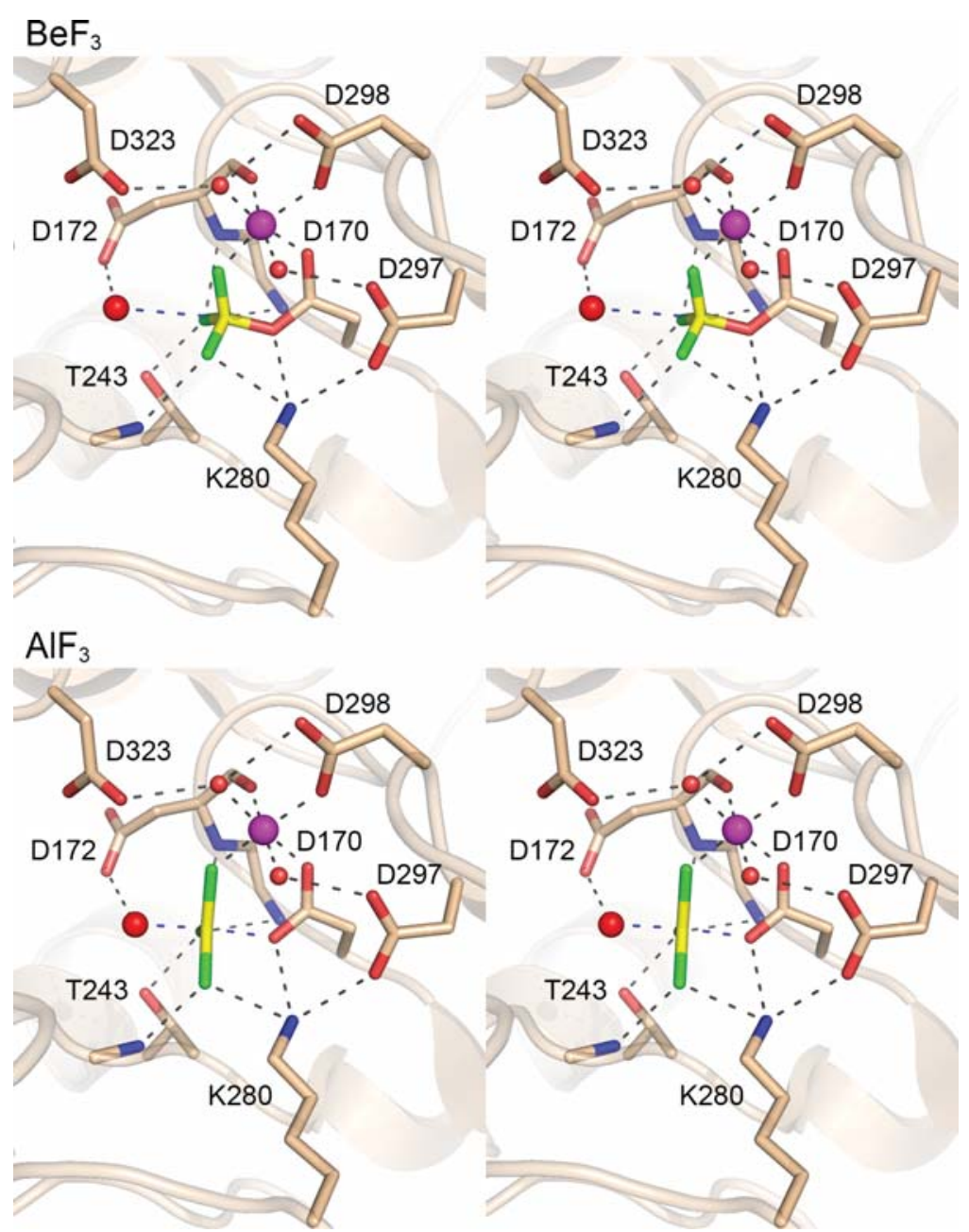

FIGURE 6. Fcpl structure captured as a mimetic of the phosphorane transition state. (Top panel) Stereo view of the active site of $\mathrm{Fcp} 1-\mathrm{BeF}_{3}$ complex that mimics the Michaelis complex of the aspartyl-phosphate hydrolysis step. (Bottom panel) Stereo view of the active site of the $\mathrm{Fcp} 1 \cdot \mathrm{AlF}_{3}$ complex that mimics the transition state of the aspartyl-phosphate hydrolysis step. Selected side chains and main chain atoms are depicted in stick representation. Octahedrally coordinated $\mathrm{Mg}^{2+}$ ions are magenta spheres. Waters are red spheres. The fluoride atoms are colored green. The beryllium and aluminum atoms are colored yellow. Atomic contacts are indicated by dashed lines.

substrate(s); such complexes have been refractory thus far to co-crystallization.

With regard to substrate repertoire, we show here that SpFcp1 is able to dephosphorylate Thr1- $\mathrm{PO}_{4}$ of the Spt5 CTD. To our knowledge, SpFcp1 is the first instance of a fission yeast Spt5 CTD threonine phosphatase. The strict essentiality of such an activity in fission yeast may be open to question in light of the findings that an spt5-CTD-T1E mutant, in which all Thrl positions are replaced by the phosphomimetic glutamate, is viable at all temperatures (Schneider et al. 2010). The Thr1- $\mathrm{PO}_{4}$ mark (installed by Cdk9) is thought to be important for the positive transcription elongation activity of fission yeast Spt5, insofar as changing all Spt5 CTD Thr1 positions to alanine sensitized S. pombe cells to growth inhibition by 5 -azauracil, whereas changing $\mathrm{Thr} 1$ to a phosphomimetic glutamate did not (Schneider et al. 2010). On the other hand, Thr1 phosphorylation antagonizes the interaction of the Spt5 CTD with the $S$. pombe mRNA capping enzymes (Doamekpor et al. 2014, 2015). Genetic evidence in fission yeast indicates that the unphosphorylated Spt5 CTD and the Ser5-phosphorylated Pol2 CTD collaborate in vivo to recruit the capping apparatus to the Pol2 elongation complex. The Fcp1 Spt5 threonine phosphatase could aid this process by ensuring availability of unphosphorylated Spt5 CTD.

Although the structural biology and biochemistry of SpFcp1 are well advanced, little was known previously about the genetics of SpFcp1, beyond its essentiality for fission yeast viability (Kimura et al. 2002). By implementing a complementation assay with biochemically characterized mutants, we show that (i) the phosphatase catalytic activity is necessary (full-length D170A is lethal), but not sufficient (catalytic domain alone is lethal), for Fcp1 function in vivo; and (ii) the $\mathrm{N}$ domain flanking the catalytic domain is essential in vivo, but the flanking $\mathrm{C}$ domain is dispensable. In contrast, the $\mathrm{N}$ and $\mathrm{C}$ domains of S. cerevisiae Fcp1 are both dispensable, though their simultaneous deletion is lethal (Kobor et al. 2000). It is posited that the $\mathrm{N}$ and $\mathrm{C}$ domains of $S$. cerevisiae Fcp1 make functionally redundant interactions with one or more components of the Pol2 elongation complex. Much attention has been paid to an acidic carboxy-terminal peptide motif in S. cerevisiae and human Fcp1 that binds TFIIF (Archambault et al. 1997; Kamada et al. 2003; Nguyen et al. 2003). Human Fcp1 has a second peptide motif proximal to its BRCT domain that interacts independently with the same docking site on TFIIF that binds the carboxy-terminal Fcp1 motif (Yang et al. 2009). In the $S$. pombe Fcp1 crystal structure (Ghosh et al. 2008), the equivalent peptide makes extensive intramolecular hydrophobic contacts that would preclude its binding to TFIIF in the mode reported for a synthetic peptide derived from human Fcp1. Moreover, the relevance of TFIIF binding to $S$. pombe Fcp1 is unclear, because available evidence points to a direct interaction of SpFcp1 with Pol2 as a likely mode of SpFcpl binding to the elongation complex (Kimura et al. 2002; Suh et al. 2005).

By alanine scanning of the SpFcp1 N domain, we identify a putative CHCC metal-binding module as uniquely essential 
for Fcp1 function in vivo. It is conceivable that the $\mathrm{N}$ domain and metal-binding module target Fcp1 to Pol2 and/or the Pol2 transcription complex at the proper time and place, to either recycle phosphorylated $\mathrm{Pol} \mathrm{II}_{\mathrm{o}}$ to unphosphorylated $\mathrm{Pol} \mathrm{II}_{\mathrm{a}}$ for a new round of transcription initiation or to modulate the CTD phosphorylation state of the Pol2 transcription complex as it traverses a gene. Structure determination of the SpFcp1 N domain, and a search for interacting partners, will be critical to understanding its function.

Our studies uncovered two novel genetic interactions of Fcp1 mutants in fission yeast. First, we found that the $R 271 A$ and $R 299 A$ alleles, which were lethal in the presence of full-length Pol2 CTD, were revived when the CTD heptad array was shortened. We surmise that the impact of certain mutations that reduce SpFcp1 CTD phosphatase activity or alter its substrate preference can be compensated in vivo by reducing the phosphatase workload, in this case by having fewer CTD phosphorylation marks to contend with when the CTD repeat array is truncated. Second, we saw that certain $f_{c p} 1$ alleles, that elicited no growth defect by themselves (e.g., missense changes along the canyon surface of a deletion of the C domain), were synthetically sick when the inessential Ssu72 phosphatase was either deleted or its active site cysteine was mutated. These results suggest that Ssu72 shares some of the workload of Fcpl in fission yeast, so that it can buffer the effects of hypomorphic SpFcp1 mutations. In the case of budding yeast, where Ssu72 is essential for viability, it was reported that the growth defect of $s s u 72$-ts mutants at $35^{\circ} \mathrm{C}$ was suppressed by overexpression of Fcp1, but not vice versa (Ganem et al. 2003).

Finally, we provide here genetic evidence that neither the Ser2- $\mathrm{PO}_{4}$ mark nor the Ser5- $\mathrm{PO}_{4}$ mark on the Pol2 CTD is a sole essential substrate for $\mathrm{SpFcp} 1$ in vivo, insofar as the lethality of catalytically dead SpFcp1 could not be bypassed by individually precluding Ser2 or Ser5 phosphorylations. Whereas it is likely that SpFcp1 is needed to erase Ser2$\mathrm{PO}_{4}$ and Ser5- $\mathrm{PO}_{4}$ marks in fission yeast, based on its competence to do so in vitro, we do not rule out the prospect that SpFcp1 might dephosphorylate Ser7- $\mathrm{PO}_{4}, \mathrm{Thr}-\mathrm{PO}_{4}$ or Tyr $1-\mathrm{PO}_{4}$ on the fission yeast Pol2 CTD (Sakurai and Ishihama 2002) or that its essential activity extends to other phospho-protein substrates. Two recent studies have invoked a Pol2 CTD Thr4 phosphatase function for Fcp1 in S. cerevisiae and chicken DT40 cells (Allepuz-Fuster et al. 2014; Hsin et al. 2014).

\section{MATERIALS AND METHODS}

\section{Allelic exchange at the $S$. pombe chromosomal fcp1 locus}

We constructed a series of pKS-based plasmids carrying an $f c p 1$ CTD integration cassette marked with hygMX. The cassettes consisted of the following elements, proceeding from $5^{\prime}$ to $3^{\prime}$ : (i) a 670 -bp segment of genomic DNA $5^{\prime}$ of the $f c p 1^{+}$start codon; (ii) an open reading frame encoding the wild-type SpFcp1 phosphatase or mutated versions thereof as specified; (iii) a 269-bp segment including termination/poly(A) signals from the $n m t 1+$ gene; (iv) a hygMX gene conferring resistance to hygromycin; and (v) a 703bp segment of genomic DNA $3^{\prime}$ of the $f c p 1^{+}$stop codon. The integration cassettes were linearized and transformed into a diploid $S$. pombe strain. Hygromycin-resistant transformants were selected and diagnostic PCR and/or Southern blotting was used to confirm correct integrations at one of the $f_{c p} 1^{+}$loci. The $f c p 1-h y g M X$ allele was amplified by PCR and sequenced to verify that the desired ORFs were present. The heterozygous $f_{c p} 1^{+} f_{c p} 1-h y g M X$ diploids were then sporulated and subjected to random spore analysis. Spores $(\sim 5000)$ were plated to YES agar medium (to gauge the number of viable offspring) and to YES medium containing 300 $\mu \mathrm{g} / \mathrm{mL}$ hygromycin. A finding that no viable hygromycin-resistant haploids were recovered after $7 \mathrm{~d}$ at $30^{\circ} \mathrm{C}$ was deemed to indicate lethality of a given $f c p 1$ mutant allele. Viable $f c p 1-h y g M X$ haploid strains formed colonies on selective agar at frequencies consistent with random segregation. To gauge the effect of the $f c p 1$ mutations on vegetative growth, cultures of haploid $S$. pombe fcp1-hygMX strains were grown in liquid medium at $30^{\circ} \mathrm{C}$ until $A_{600}$ reached $0.6-0.9$. The cultures were adjusted to a final $A_{600}$ of 0.1 and aliquots $(3 \mu \mathrm{L})$ of serial fivefold dilutions were spotted on YES agar. The plates were incubated at $18^{\circ} \mathrm{C}$ or $20^{\circ} \mathrm{C}, 25^{\circ} \mathrm{C}, 30^{\circ} \mathrm{C}$, $34^{\circ} \mathrm{C}$, and $37^{\circ} \mathrm{C}$.

\section{Recombinant SpFcp1}

DNAs encoding SpFcp1(140-580) and SpFcp1 $\Delta 330-393$ (Ghosh et al. 2008) were inserted into pSMT3 (Mossessova and Lima 2000) to generate plasmids encoding $\mathrm{His}_{6} \mathrm{Smt} 3-\mathrm{SpF}$ cp1 fusion proteins under the control of a bacteriophage T7 promoter. Mutation R271A was introduced into the $\mathrm{His}_{6} \mathrm{Smt}_{3}-\mathrm{SpF}$ cp1 $\Delta 330-393$ plasmid. The plasmids inserts were sequenced completely to exclude the acquisition of unwanted coding changes during amplification and cloning. The plasmids were transformed into E. coli BL21 (DE3) CodonPlus RIL (Novagen). Four-liter bacterial cultures were grown at $37^{\circ} \mathrm{C}$ in Super Broth (Teknova) supplemented with $50 \mu \mathrm{g} / \mathrm{mL}$ kanamycin and $100 \mu \mathrm{g} / \mathrm{mL}$ chloramphenicol in baffled flasks until $A_{600}$ reached 2.0. The temperature was then reduced to $18^{\circ} \mathrm{C}$, isopropyl- $\beta$-D-thiogalactoside (IPTG) was added to $0.5 \mathrm{mM}$, and the cultures were incubated overnight. Cells were harvested by centrifugation at $14,000 \mathrm{~g}$ and resuspended in buffer containing $20 \mathrm{mM}$ Tris- $\mathrm{HCl}$ (pH 8.0), $500 \mathrm{mM} \mathrm{NaCl}, 20 \mathrm{mM}$ imidazole, $0.1 \%$ IGEPAL, $20 \%$ sucrose, $1 \mathrm{mM} \beta$-mercaptoethanol (BME). Cells were disrupted by sonication and debris was removed by centrifugation at $45,000 \mathrm{~g}$. The supernatants were applied to $10 \mathrm{~mL}$ Ni-NTA agarose columns that had been equilibrated with buffer A $(50 \mathrm{mM}$ Tris- $\mathrm{HCl}$ at $\mathrm{pH} 8.0,15 \mathrm{mM}$ imidazole, $500 \mathrm{mM} \mathrm{NaCl}, 1 \mathrm{mM}$ BME). The columns were washed with buffer A and the $\mathrm{His}_{6} \mathrm{Smt} 3-$ SpFcpl proteins were eluted with buffer B $(20 \mathrm{mM}$ Tris- $\mathrm{HCl}$ at $\mathrm{pH}$ 8.0, $350 \mathrm{mM} \mathrm{NaCl}, 150 \mathrm{mM}$ imidazole, $1 \mathrm{mM} \mathrm{BME})$. The $\mathrm{His}_{6} \mathrm{Smt} 3$ tags were removed by overnight digestion at $4^{\circ} \mathrm{C}$ with the Smt3-specific protease Ulp1 (Mossessova and Lima 2000) at a 2000:1 ratio of SpFcp1:Ulp1. The tag-free Fcp1 proteins were then separated from $\mathrm{His}_{6} \mathrm{Smt} 3$ by Superdex 200 gel filtration in buffer containing $20 \mathrm{mM}$ Tris- $\mathrm{HCl}$ at $\mathrm{pH} 8.0,350 \mathrm{mM} \mathrm{NaCl}, 1 \mathrm{mM}$ BME. Peak fractions were pooled and concentrated to $20-25 \mathrm{mg} / \mathrm{mL}$ in $20 \mathrm{mM}$ Tris- $\mathrm{HCl}$ at $\mathrm{pH}$ 8.0, $50 \mathrm{mM} \mathrm{NaCl}, 5 \mathrm{mM}$ DTT. 


\section{Crystallization and structure determination}

Aluminum fluoride complex: A solution comprising $300 \mu \mathrm{M}$ SpFcp1 $\Delta 330-393-(\mathrm{R} 271 \mathrm{~A})$ mutant protein with $600 \mu \mathrm{M} \mathrm{AlCl}$, $5 \mathrm{mM} \mathrm{NaF}, 5 \mathrm{mM} \mathrm{MgCl}_{2}$, and $500 \mu \mathrm{M}$ CTD peptide SPSYSPTSPS was incubated for $1 \mathrm{~h}$ on ice prior to crystallization by sitting drop vapor diffusion against 35\% PEG-550MME, $100 \mathrm{mM} \mathrm{MES} \mathrm{(pH} \mathrm{6.5).}$ Beryllium fluoride complex: A solution of $300 \mu \mathrm{M}$ SpFcp1 $\Delta 330$ 393, $600 \mu \mathrm{M} \mathrm{BeCl}_{2}, 5 \mathrm{mM} \mathrm{NaF}$, and $5 \mathrm{mM} \mathrm{MgCl}$ was incubated for $1 \mathrm{~h}$ on ice prior to crystallization by sitting drop vapor diffusion against 40\% PEG-400, 100 mM MES (pH 6.5). The crystals were flash frozen in liquid nitrogen. Diffraction data at $1.45 \AA$ resolution for the $\mathrm{AlF}_{3}$ complex and $1.85 \AA$ resolution for the $\mathrm{BeF}_{3}$ complex were collected at the Advanced Photon Source (Argonne) at NE-CAT beamline 24-ID (Table 1). Data reduction was achieved with SCALEPACK (Otwinowski and Minor 1997) and CCP4 (CCP4 1994). Both crystals were in space group $\mathrm{P} 2{ }_{1} 2_{1} 2_{1}$ with a single $\mathrm{Fcp} 1$ protomer in the asymmetric unit. The structures were solved by molecular replacement using as a search model a prior Fcp1 polypeptide structure (pdb 3EF0) from which nonprotein ligands, metal, and waters were omitted. Atomic models were built into the electron density with Coot (Emsley and Cowtan 2004), and refined with Refmac and Phenix (Adams et al. 2010). Waters were added during refinements in Phenix and checked manually. Model quality and geometry were validated in MolProbity (Table 1; Chen et al. 2010).

\section{CTD phosphatase assay}

The Pol2 CTD substrates were a 28 -aa synthetic peptide in which all Ser5 positions were phosphorylated YSPTS $_{5 \mathrm{P}}$ PSYSPTS $_{5 \mathrm{P}} \mathrm{PSYSPTS}_{5 \mathrm{P}}$ PSYSPTS $_{5 \mathrm{P} P S}$ ) or a 28 -aa synthetic peptide in which all Ser2 positions were phosphorylated YS $_{2 \mathrm{P}}$ PTSPSYS $_{2 \mathrm{P}}$ PTSPSYS $_{2 \mathrm{P}}$ PTSPSYS $_{2 \mathrm{P}}$ PTSPS). The Spt5 CTD substrate was a 22-aa synthetic peptide in which Thr1 positions were phosphorylated SGSKT $_{1 P}$ PAWNSGSKT $_{1 \mathrm{P}} \mathrm{PAWNSGSK}$ ). The content of Ser-PO $\mathrm{PO}_{4}$ (for the Pol2 CTD peptides) and Thr1- $\mathrm{PO}_{4}$ (for the Spt5 CTD peptide) was determined by measuring the release of inorganic phosphate after incubating the phosphopeptides with 0.5 unit of alkaline phosphatase (CIP, New England Biolabs) at $37^{\circ} \mathrm{C}$ for 2 h. CTD phosphatase reaction mixtures $(25 \mu \mathrm{L})$ containing $50 \mathrm{mM}$ Tris-acetate $(\mathrm{pH} 5.5)$, $10 \mathrm{mM} \mathrm{MgCl}_{2}, 25 \mu \mathrm{M}$ Pol2 CTD or $50 \mu \mathrm{M}$ Spt5 CTD phosphopeptide substrates, and 0.05 to $0.8 \mu \mathrm{M}$ SpFcp1-(140-580) proteins were incubated at $37^{\circ} \mathrm{C}$ for $45 \mathrm{~min}$. The reactions were quenched by adding $100 \mu \mathrm{L}$ malachite green reagent (BIOMOL green; BIOMOL Research Laboratories). The samples were incubated at room temperature for 30 min before measuring $A_{620}$ with a SPECTRAmax Plus (Molecular Device, Inc.) spectrophotometer. Inorganic phosphate $\left(\mathrm{P}_{\mathrm{i}}\right)$ was quantified by interpolating the absorbance values to a standard curve derived from $\mathrm{KH}_{2} \mathrm{PO}_{4}$ diluted in reaction buffer. $\mathrm{P}_{\mathrm{i}}$ release (normalized to reaction time) was plotted as a function of input $\mathrm{SpF}$ cp1 concentration. Error bars denote the SEM calculated from three independent experiments that were each performed in triplicate. The titration data were fit by linear regression in Prism to derive the specific activity values.

\section{DATA DEPOSITION}

Structure factors and coordinates have been deposited in the RCSB Protein Data Base with accession codes $4 \mathrm{XPZ}\left(\mathrm{AlF}_{3}\right.$ complex) and 4XQ0 ( $\mathrm{BeF}_{3}$ complex).

\section{ACKNOWLEDGMENTS}

Use of the Advanced Photon Source (APS) is supported by the US Department of Energy, Office of Basic Energy Sciences, under Contract No. DE-AC02-06CH11357. Use of the APS on the NECAT beamlines are supported by award GM103403 from the NCRR at the National Institutes of Health (NIH). A.G. was supported in part by a Human Frontier Science Fellowship. C.D.L. is an Investigator of the Howard Hughes Medical Institute. S.S. is an American Cancer Society Research Professor. This work was supported by the Office of Extramural Research of the NIH, grants GM052470 (S.S. and B.S.) and GM061906 (C.D.L.).

Received January 19, 2015; accepted February 25, 2015.

\section{REFERENCES}

Adams PD, Afonine PV, Bunkóczi G, Chen VB, Davis IW, Echols N, Headd JJ, Hung LW, Kapral GJ, Grosse-Kunstleve RW, et al. 2010. PHENIX: a comprehensive Python-based system for macromolecular structure solution. Acta Crystallogr D Biol Crystallogr 66: 213-221.

Allepuz-Fuster P, Martínez-Fernández V, Garrido-Godino AI, AlonsoAguado S, Hanes SD, Navarro F, Calvo O. 2014. Rpb4/7 facilitates RNA polymerase II CTD dephosphorylation. Nucleic Acids Res 42: 13674-13688.

Archambault J, Chambers RS, Kobor MS, Ho Y, Cartier M, Bolotin D, Andrews B, Kane CM, Greenblatt J. 1997. An essential component of a C-terminal domain phosphatase that interacts with transcription factor IIF in Saccharomyces cerevisiae. Proc Natl Acad Sci 94: 14300-14305.

Bentley DL. 2014. Coupling mRNA processing with transcription in time and space. Nat Rev Genet 15: 163-175.

Burroughs AM, Allen KN, Dunaway-Mariano D, Aravind L. 2006. Evolutionary genomics of the HAD superfamily: understanding the structural adaptations and catalytic diversity in a superfamily of phosphoesterases and allied enzymes. J Mol Biol 361: 1003-1034.

CCP4. 1994. The CCP4 suite: programs for protein crystallography. Acta Crystallogr D Biol Crystallogr 50: 760-763.

Chambers RS, Dahmus ME. 1994. Purification and characterization of a phosphatase from HeLa cells which dephosphorylates the C-terminal domain of RNA polymerase II. J Biol Chem 269: 26243-26248.

Chambers RS, Kane CM. 1996. Purification and characterization of an RNA polymerase II phosphatase from yeast. J Biol Chem 271: 24498-24504.

Chen VB, Arendall WB III, Headd JJ, Keedy DA, Immormino RM, Kapral GJ, Murray LW, Richardson JS, Richardson DC. 2010. MolProbity: all-atom structure validation for macromolecular crystallography. Acta Crystallogr D Biol Crystallogr 66: 12-21.

Cho H, Kim TK, Mancebo H, Lane WS, Flores O, Reinberg D. 1999. A protein phosphatase functions to recycle RNA polymerase II. Genes Dev 13: $1540-1552$.

Corden JL. 2013. RNA polymerase II C-terminal domain: tethering transcription to transcript and template. Chem Rev 113: 8423-8455.

Daughtry KD, Huang H, Malashkevich V, Patskovsky Y, Liu W, Ramagopal U, Sauder JM, Burley SK, Almo SC, DunawayMariano D, et al. 2013. Structural basis for the divergence of substrate specificity and biological function within HAD phosphatases in lipopolysaccharide and sialic acid biosynthesis. Biochemistry 52: 5372-5386.

Doamekpor SK, Sanchez AM, Schwer B, Shuman S, Lima CD. 2014. How an mRNA capping enzyme reads distinct RNA polymerase II and Spt5 CTD phosphorylation codes. Genes Dev 28: 1323-1336.

Doamekpor SK, Schwer B, Sanchez AM, Shuman S, Lima CD. 2015. Fission yeast RNA triphosphatase reads an Spt5 CTD code. RNA 21: 113-123. 
Eick D, Geyer M. 2013. The RNA polymerase II carboxy-terminal domain (CTD) code. Chem Rev 113: 8456-8490.

Emsley P, Cowtan K. 2004. Coot: model-building tools for molecular graphics. Acta Crystallogr D Biol Crystallogr 60: 2126-2132.

Fuda NJ, Buckley MS, Wei W, Core LJ, Waters CT, Reinberg D, Lis JT. 2012. Fcp1 dephosphorylation of the RNA polymerase II C-terminal domain is required for efficient transcription of heat shock genes. Mol Cell Biol 32: 3428-3437.

Ganem C, Devaux F, Torchet C, Jacq C, Quevillon-Cheruel S, Labesse G, Facca C, Faye G. 2003. Ssu72 is a phosphatase essential for transcription termination of snoRNAs and specific mRNAs in yeast. EMBO $J$ 22: $1588-1598$.

Ghosh A, Shuman S, Lima CD. 2008. The structure of Fcp1, an essential RNA polymerase II CTD phosphatase. Mol Cell 32: 478-490.

Hartzog GA, Fu J. 2013. The Spt4-Spt5 complex: a multi-faceted regulator of transcription elongation. Biochim Biophys Acta 1829: $105-115$.

Hausmann S, Shuman S. 2002. Characterization of the CTD phosphatase Fcp1 from fission yeast: preferential dephosphorylation of serine 2 versus serine 5. J Biol Chem 277: 21213-21220.

Hausmann S, Shuman S. 2003. Defining the active site of Schizosaccharomyces pombe C-terminal domain phosphatase Fcp1. J Biol Chem 278: $13627-13632$.

Hausmann S, Erdjument-Bromage H, Shuman S. 2004. Schizosaccharomyces pombe carboxyl-terminal domain (CTD) phosphatase Fcp1: distributive mechanism, minimal CTD substrate, and active site mapping. J Biol Chem 279: 10892-10900.

Hausmann S, Koiwa H, Krishnamurthy S, Hampsey M, Shuman S. 2005. Different strategies for carboxyl-terminal domain (CTD) recognition by Serine5-specific CTD phosphatases. J Biol Chem 280: 37681-37688.

Hsin JP, Xiang K, Manley JL. 2014. Function and control of RNA polymerase II C-terminal domain phosphorylation in vertebrate transcription and RNA processing. Mol Cell Biol 34: 2488-2498.

Kamada K, Roeder RG, Burley SK. 2003. Molecular mechanism of recruitment of TFIIF-associating RNA polymerase C-terminal domain phosphatase (FCP1) by transcription factor IIF. Proc Natl Acad Sci 100: 2296-2299.

Kimura M, Suzuki H, Ishihama A. 2002. Formation of a carboxy-terminal domain phosphatase (Fcp1)/TFIIF/RNA polymerase II (pol II) complex in Schizosaccharomyces pombe involves direct interaction between Fcp1 and the Rpb4 subunit of pol II. Mol Cell Biol 22: 1577-1588.

Kobor MS, Archambault J, Lester W, Holstege FC, Gileadi O, Jansma DB, Jennings EG, Kouyoumdjian F, Davidson AR, Young RA, et al. 1999. An unusual eukaryotic protein phosphatase required for transcription by RNA polymerase II and CTD dephosphorylation in S. cerevisiae. Mol Cell 4: 55-62.

Kobor MS, Simon LD, Omichinski J, Zhong G, Archambault J, Greenblatt J. 2000. A motif shared by TFIIF and TFIIB mediates their interaction with the RNA polymerase II carboxy-terminal domain phosphatase Fcplp in Saccharomyces cerevisiae. Mol Cell Biol 20: 7438-7449.

Krishnamurthy S, He X, Reyes-Reyes M, Moore C, Hampsey M. 2004. Ssu72 is an RNA polymerase II CTD phosphatase. Mol Cell 14: 387-394.

Lahiri SD, Zhang G, Dunaway-Mariano D, Allen KN. 2003. The pentacovalent phosphorus intermediate of a phosphoryl transfer reaction. Science 299: 2067-2071.

Lu Z, Dunaway-Mariano D, Allen KN. 2008. The catalytic scaffold of the haloalkanoic acid dehalogenase enzyme superfamily acts as a mold for the trigonal bipyramidal transition state. Proc Natl Acad Sci 105: 5687-5692.

Mossessova E, Lima CD. 2000. Ulp1-SUMO crystal structure and genetic analysis reveal conserved interactions and a regulatory element essential for cell growth in yeast. Mol Cell 5: 865-876.
Nguyen BD, Abbott KL, Potempa K, Kobor MS, Archambault J, Greenblatt J, Legault P, Omichinski JG. 2003. NMR structure of a complex containing the TFIIF subunit RAP74 and the RNA polymerase II carboxyl-terminal domain phosphatase FCP1. Proc Natl Acad Sci 100: 5688-5693.

Otwinowski Z, Minor W. 1997. Processing of X-ray diffraction data collected in oscillation mode. Methods Enzymol 276: 307-326.

Pei Y, Shuman S. 2002. Interactions between fission yeast mRNA capping enzymes and elongation factor Spt5. J Biol Chem 277: 19639-19648.

Pei Y, Shuman S. 2003. Characterization of the Schizosaccharomyces pombe Cdk9/Pch1 protein kinase: Spt5 phosphorylation, autophosphorylation, and mutational analysis. J Biol Chem 278: 43346-43356.

Pei Y, Hausmann S, Ho CK, Schwer B, Shuman S. 2001. The length, phosphorylation state, and primary structure of the RNA polymerase II carboxyl-terminal domain dictate interactions with mRNA capping enzymes. J Biol Chem 276: 28075-28082.

Sajiki K, Hatanaka M, Nakamura T, Takeda K, Shimanuki M, Yoshida T, Hanyu Y, Hayashi T, Nakaseko Y, Yanagida M. 2009. Genetic control of cellular quiescence in S. pombe. J Cell Sci 122: 1418-1429.

Sakurai H, Ishihama A. 2002. Level of the RNA polymerase II in the fission yeast stays constant but phosphorylation of its carboxyl terminal domain varies depending on the phase and rate of cell growth. Genes Cells 7: 273-284.

Schneider S, Pei Y, Shuman S, Schwer B. 2010. Separable functions of the fission yeast Spt5 carboxyl-terminal domain (CTD) in capping enzyme binding and transcription elongation overlap with those of the RNA polymerase II CTD. Mol Cell Biol 30: 2353-2364.

Schwer B, Shuman S. 2011. Deciphering the RNA polymerase II CTD code in fission yeast. Mol Cell 43: 311-318.

Schwer B, Sanchez AM, Shuman S. 2012. Punctuation and syntax of the RNA polymerase II CTD code in fission yeast. Proc Natl Acad Sci 109: 18024-18029.

Schwer B, Bitton DA, Sanchez AM, Bähler J, Shuman S. 2014. Individual letters of the RNA polymerase II CTD code govern distinct gene expression programs in fission yeast. Proc Natl Acad Sci 111: 4185-4190.

Suh MH, Ye P, Zhang M, Hausmann S, Shuman S, Gnatt AL, Fu J. 2005. Fcp1 directly recognizes the C-terminal domain (CTD) and interacts with a site on RNA polymerase II distinct from the CTD. Proc Natl Acad Sci 102: 17314-17319.

Tombácz I, Schauer T, Juhász I, Komonyi O, Boros I. 2009. The RNA Pol II CTD phosphatase Fcp1 is essential for normal development in Drosophila melanogaster. Gene 446: 58-67.

Varon R, Gooding R, Steglich C, Marns L, Tang H, Angelicheva D, Yong KK, Ambrugger P, Reinhold A, Morar B, et al. 2003. Partial deficiency of the C-terminal-domain phosphatase of RNA polymerase II is associated with congenital cataracts facial dysmorphism neuropathy syndrome. Nat Genet 35: 185-189.

Viladevall L, St Amour CV, Rosebrock A, Schneider S, Zhang C, Allen JJ, Shokar KM, Schwer B, Leatherwood JK, Fisher RPl. 2009. TFIIH and $\mathrm{P}-\mathrm{TEFb}$ coordinate transcription with capping enzyme recruitment at specific genes in fission yeast. Mol Cell 33: 738-751.

Wang W, Cho HS, Kim R, Jancarik J, Yokota H, Nguyen HH, Grigoriev IV, Wemmer DE, Kim SH. 2002. Structural characterization of the reaction pathway in phosphoserine phosphatase: crystallographic "snapshots" of intermediate states. J Mol Biol 319: 421-431.

Yang A, Abbott KL, Desjardins A, De Lello P, Omichinski JG, Legault P. 2009. NMR structure of a complex formed by the carboxyl-terminal domain of human RAP74 and a phosphorylated peptide from the central domain of the FCP1 phosphatase. Biochemistry 48: 19641974.

Zhang Y, Zhang M, Zhang Y. 2011. Crystal structure of Ssu72, an essential eukaryotic phosphatase specific for the carboxy-terminal domain of RNA polymerase II, in complex with a transition state analog. Biochem J 434: 435-444. 

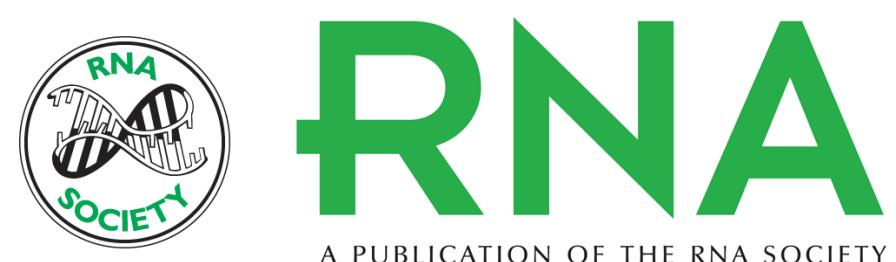

A PUBLICATION OF THE RNA SOCIETY

\title{
Genetic and structural analysis of the essential fission yeast RNA polymerase II CTD phosphatase Fcp1
}

\author{
Beate Schwer, Agnidipta Ghosh, Ana M. Sanchez, et al.
}

RNA 2015 21: 1135-1146 originally published online April 16, 2015

Access the most recent version at doi:10.1261/rna.050286.115

\begin{abstract}
References This article cites 51 articles, 28 of which can be accessed free at: http://rnajournal.cshlp.org/content/21/6/1135.full.html\#ref-list-1

Creative This article is distributed exclusively by the RNA Society for the first 12 months after the Commons full-issue publication date (see http://rnajournal.cshlp.org/site/misc/terms.xhtml). After 12 License months, it is available under a Creative Commons License (Attribution-NonCommercial 4.0 International), as described at http://creativecommons.org/licenses/by-nc/4.0/.
\end{abstract}

Email Alerting Receive free email alerts when new articles cite this article - sign up in the box at the Service top right corner of the article or click here.

To subscribe to $R N A$ go to:

http://rnajournal.cshlp.org/subscriptions 